number of eosinophilic granules in the eosinophils, but it is clear that these characteristics caused mistakes in counting the numbers of eosinophils with automated haematological analysers, especially using the electrical impedance method and alkaline treatment.

\section{Conclusion}

These data indicate that it is important during haematological examination to include a check of the blood films when cell counts measured by an automated analyser are apparently abnormal.

1 Williams WJ, Douglas AN, Michael WM. Examination of the blood. In: Williams WJ, Erslev AJ, Lichiman MA, eds. Hematology. 4th edn. New York: McGraw-Hill, 1990:9-24.

2 Wardlaw AJ, Kay AB. Eosinopenia and eosinophilia. In Williams WJ, Ernest B, eds. Hematology. 5th edn. New York: McGraw-Hill, 1995:844-51.

3 Science document. I. Basic specifications 2. Principles. Kobe: Toa medical electric corporation. 1993:2A-B.

\title{
Bronchial mucoepidermoid carcinoma after allogeneic bone marrow transplantation
}

\author{
J Sánchez, J Serrano, P Gómez, J Román, A Cosano, A Torres
}

\begin{abstract}
A 16 year old man underwent an allogeneic bone marrow transplantation (BMT) from an HLA identical sibling donor for acute lymphoblastic leukaemia in 1984. He developed chronic graft versus host disease involving the skin and kidneys. At day 400 after BMT his condition was complicated by obstructive airways disease, which was partially responsive to azathioprine and steroids. Five years after withdrawal of immunosuppressive treatment he developed dyspnoea and decreased pulmonary function test results, and steroid treatment was resumed. Fibrobronchoscopy revealed the presence of a mucoepidermoid carcinoma in the left main bronchus. After surgical laser resection, there was gradual clinical and functional improvement. There was no evidence of recurrence one year after surgery.

(f Clin Pathol 1997;50:969-970)
\end{abstract}

Keywords: bone marrow transplantation; obstructive airways disease; mucoepidermoid carcinoma

Bone marrow transplantation (BMT) has become the treatment of choice for a variety of haematological and non-haematological disorders. A wide range of pulmonary complications has been associated with the procedure; resulting from pretransplant chemoradiation, infections, and graft versus host disease (GVHD). Late (more than 100 days after BMT) pulmonary complications include: fibrosis, idiopathic interstitial pneumonia, restrictive disease, and bronchiolitis obliterans. ${ }^{2}$ Airflow obstruction after BMT has classically been associated with chronic GVHD, the use of methotrexate as prophylaxis against acute GVHD, and low serum immunoglobulin concentrations. Management of these patients includes immunosuppressive treatment although its role remains undetermined. ${ }^{3}$ The development of a second neoplasm after BMT occurs in $2 \%$ of cases but rarely involves the lung. ${ }^{45} \mathrm{~A}$ second neoplasm in the lung in a long survivor of bronchiolits obliterans after BMT has not previously been reported.

\section{Case report}

A 16 year old man presented with acute lymphoblastic leukaemia in 1984. After chemotherapy including prednisone, vincristine, anthracyclins, and methotrexate, complete remission was attained. $\mathrm{He}$ underwent allogeneic BMT from an HLA identical sibling donor. $\mathrm{He}$ had no previous history of lung disease, and pulmonary function tests and chest radiography were normal before the procedure. As a conditioning regimen he received cyclophosphamide $(120 \mathrm{mg} / \mathrm{kg})$ and total body irradiation (lung dose, 700 rads). His initial condition was complicated by grade II acute GVHD involving the skin and intestine. Seven months after BMT he developed chronic GVHD involving the skin (incontinentia pigmenti) and kidneys (nephrotic syndrome) ${ }^{6}$ which was treated with prednisone.

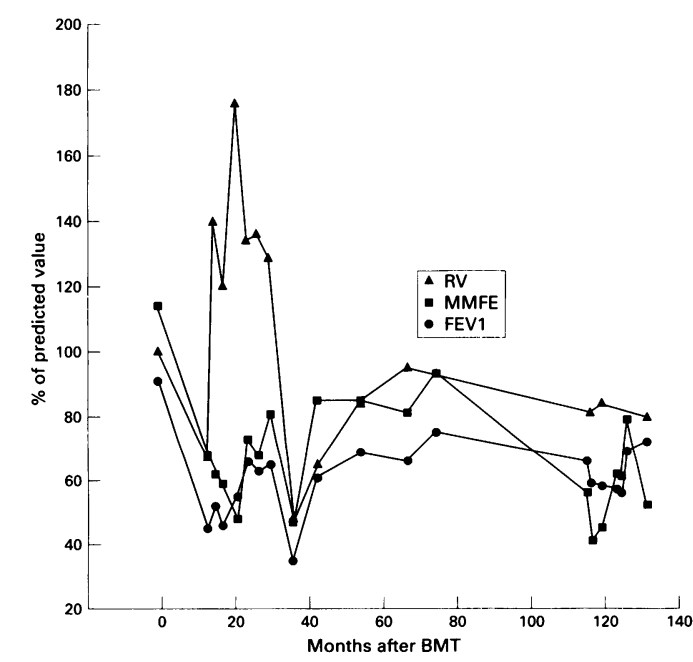

Figure 1 Long term follow up of pulmonary function tests from diagnosis of chronic airways obstruction. FEV1, forced expiratory volume in one second; $M M F E$, maximum mid-expiratory flow rate at $50 \%$ vital capacity; $R V$, residual volume. 

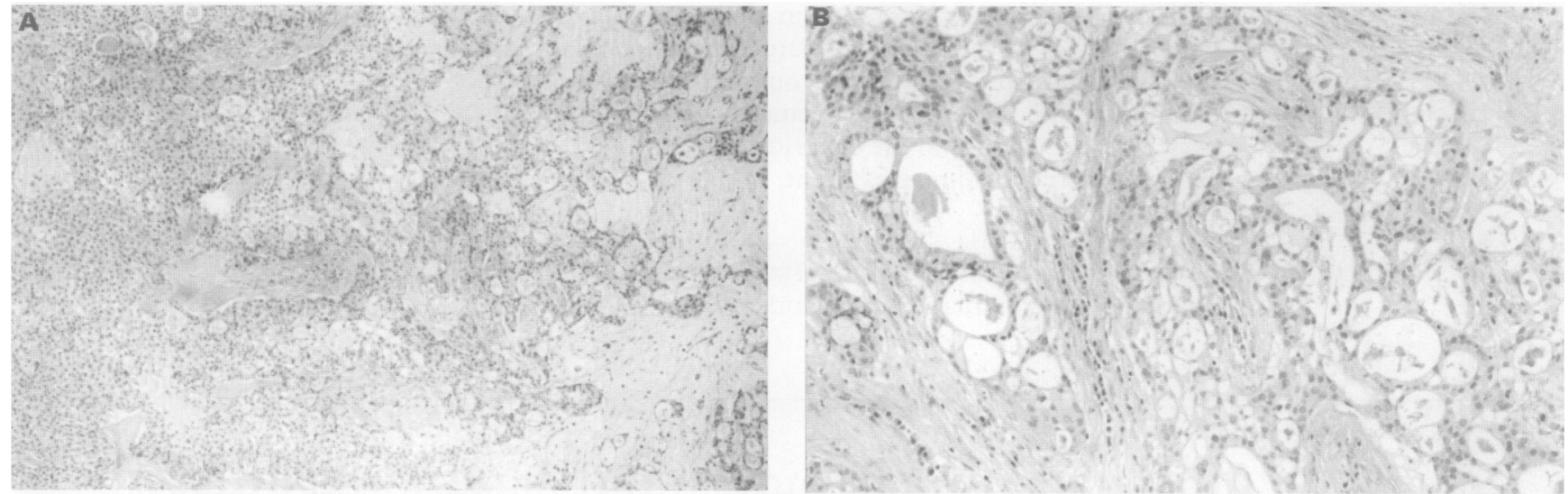

Figure 2 (A) Bronchial mucoepidermoid tissue showing an admix pattern. In the left field a solid non-keratinised epidermoid component, and in the right field the mucoid component (haematoxylin and eosin, original magnification $\times 40$ ). (B) Bronchial mucoepidermoid tissue showing mainly mucoid component (haematoxylin and eosin, original magnification $\times 300$ ).

Thirteen months after BMT while on corticosteroid treatment, he developed exertional dyspnoea, and chest radiography showed minimal patchy infiltrates. Pulmonary function tests demonstrated non-reversible airflow obstruction with air trapping and diffusing capacity for carbon monoxide decreased. Bronchoscopy and bronchoalveolar lavage showed non-specific changes with no infectious agent. Azathioprine and salbuterol inhalators were added with gradual clinical and functional improvement. Two years later the patient continued to do well, and administration of immunosuppressive treatment was tapered (fig 1).

In 1994 he reported a deterioration of symptoms with increased exertional dyspnoea. Pulmonary function tests revealed a decreased forced expiratory volume in one second (FEV1). Computed tomography showed dilatation of the small airways but fibrobronchoscopic study showed the presence of a neoformation in the left bronchus near the carina. Pathological findings of the bronchoscopic biopsy were diagnostic of low grade mucoepidermoid carcinoma (fig 2). Surgical laser resection was successfully performed with improved clinical symptoms and pulmonary function tests. There was no evidence of recurrence one year after surgery.

\section{Discussion}

BMT is the treatment of choice for a variety of haematological disorders and some solid neoplasms. The main limitation to an improvement in overall survival rates is mortality related to the procedure itself. In this regard, pulmonary injuries play an important role in the clinical outcome of BMT. The wide spectrum of pulmonary disease is believed to be multifactorial and can be a consequence of pretransplant chemoradiation, infection, pancytopenia, and GVHD. Chronic pulmonary complications are defined as occurring more than 100 days after transplantation and most of them occur within the first year. These include infectious diseases (bacterial, viral or protozoal), restrictive lung disease, and obstructive airways disease (due to bronchiolitis obliterans). However, the appearance of a second neoplasm is rarely reported in the lung. In two recent reviews, malignant neoplasms following BMT occurred in $2 \%$ of recipients; these included B lymphoproliferative disorders, myelodysplastic syndromes, and solid nonhaematopoietic tumours ${ }^{45}$ such as melanoma, brain tumours, and basal cell carcinoma.

Mucoepidermoid carcinoma usually appears in the salivary glands ${ }^{7}$ and has also been reported to involve the thymus, larynx, thyroid, and pancreas. Mucoepidermoid tumours of the lungs are rare tumours derived from the minor salivary gland tissue of the proximal tracheobronchial tree. To the best of our knowledge, this is the first report of low grade mucoepidermoid carcinoma in the lung as a second neoplasm after BMT for acute lymphoblastic leukaemia although we cannot exclude its appearance as an epiphenomenon.

It is noteworthy that recipients of BMT have a threefold increased risk of developing solid malignancies compared with the general population. Physicians must be alert to certain suspicious symptoms. This high risk is probably due to the mutagenic action of chemoradiotherapy used as a conditioning regimen for BMT, immunological injuries in organ targets of GVHD, and the oncogenic effects of immunosuppressive treatments. Furthermore, bearing in mind that no complete explanation of the immunological lung damage attributed to chronic GVHD has been given to date, ${ }^{8}$ we suggest that it is necessary to clarify the role of immunosuppressive treatment in the management of these patients. It is well known that these agents could pose an additional risk factor for the development of a second malignancy.

1 Quabeck K. The lung as critical organ in marrow transplantation. Bone Marrow Transplant 1994;14(suppl 4):S19-28.

2 Breuer R, Lossos IS, Berkman N, Or R. Pulmonary complications of bone marrow transplantation. Respir Med 1993;87:571-9.

3 Clark JG, Crawford SW, Madtes DK, Sullivan KM Obstructive lung disease after allogeneic marrow transplantation. Ann Intern Med 1989;111:368-376.

4 Bhatia S, Ramsay N, Steinbuch M, Dusenberg K, Shapiro $\mathrm{R}$, Weisdorf $\mathrm{D}$, et al. Malignant neoplasms following bone marrow transplantation. Blood 1996;87:3633-9.

5 Curtis RE, Rowlings PA, Deeg HJ, Shriner DA, Socié G, Curtis RE, Rowlings PA, Deeg HJ, Shriner DA, Socié G, Travis LB, et al. Solid cancers after bone
transplantation. $N$ Engl $f$ Med 1997;336:897-904.

6 Gómez P, Herrera C, Torres A, Gómez J, Aljama P, López F, et al. Renal involvement in chronic GVHD: a report of two cases. Bone Marrow Transplant 1988;3:357-62.

7 Ussmuller J, Donath K, Hartwein J. Site and epidemiology of mucoepidermoid carcinoma. Analysis of 327 cases Laryngorhinootologie 1994;73:478-81.

8 Yousem SA. The histological spectrum of pulmonary graftversus-host disease in bone marrow transplant recipients. Hum Pathol 1995;26:668-75. 